\title{
Lack of nutritional knowledge among Norwegian medical students concerning vegetarian diets
}

\author{
Ingebjørg Sanne ${ }^{1} \cdot$ Anne-Lise Bjørke-Monsen ${ }^{2,3}$ (i)
}

Received: 11 March 2020 / Accepted: 22 May 2020 / Published online: 3 June 2020

(C) The Author(s) 2020

\begin{abstract}
Aim Vegetarian diets are increasingly popular, particularly among young women. However, exclusion of animal products from the diet increases the risk of micronutrient deficiencies, which is particularly unfortunate during pregnancy and childhood. A person needs a substantial amount of nutritional knowledge to achieve a nutritionally complete vegetarian diet. We have tested nutritional knowledge among well-educated young vegetarians and omnivores.

Subjects and methods In October 2018, medical students at the University of Bergen, Norway $(N=880)$, were invited to take an anonymous survey to test their nutritional knowledge concerning micronutrients in vegetarian diets.

Results The responses from the students $(n=394,45 \%)$ were categorized according to diet: former or current vegetarians $(24 \%)$ versus always omnivores (76\%). Forty-five percent of the vegetarians and $28 \%$ of the omnivores did not consider it necessary to take supplements while following a vegetarian diet. Sixty-one percent of vegetarians and $38 \%$ of omnivores considered it possible to have a well-balanced vegan diet. Plant foods were wrongly considered to be a dietary source of vitamin B12 by $33 \%$ and of iodine by $20 \%$ of the students.

Conclusion Nutritional knowledge concerning vegetarian diets was not optimal among Norwegian medical students, even if they had ever followed a vegetarian diet. As vegetarian diets are popular among the younger generation and pose a risk of micronutrient deficiencies, this is a public health concern. Nutrition education should be improved in the population. A more extensive integration of nutritional training in the medical curriculum must be implemented so doctors can give adequate nutritional guidance.
\end{abstract}

Keywords Nutritional knowledge $\cdot$ Vegetarian $\cdot$ Medical student $\cdot$ Micronutrient deficiency

\section{Background}

For decades, a mixed, balanced diet including both plant and animal foods has been the dominant nutritional regime in the Nordic countries (Helsedirektoratet 2011). As vegetarian diets have become increasingly popular in recent years, this regime has been challenged (Alles et al. 2017). There are no official estimates of the prevalence of vegetarianism, but surveys and polls conducted by vegetarian societies have estimated the

Anne-Lise Bjørke-Monsen

almo@helse-bergen.no

1 Faculty of Medicine, University of Bergen, Bergen, Norway

2 Department of Clinical Science, University of Bergen, Bergen, Norway

3 Department of Medical Biochemistry and Pharmacology, Haukeland University Hospital, Bergen, Norway prevalence to vary between $1 \%$ and $10 \%$ for Western countries (Alles et al. 2017; TheVeganSociety 2019).

Vegetarians predominantly consume plant food; lacto-ovo vegetarians avoid all meat and fish, but do consume dairy products and eggs, while vegans avoid all animal products (Melina et al. 2016). The American Academy of Nutrition and Dietetics consider well-planned vegetarian diets, including vegan diets, to be appropriate during all stages of life, including pregnancy, lactation, infancy, childhood and adolescence (Melina et al. 2016). However, total elimination of animal products from the diet increases the risk of vitamin B12, vitamin D, vitamin A, zinc, selenium, calcium, iodine and iron deficiency (Davey et al. 2003; Elorinne et al. 2016; Schupbach et al. 2017). These micronutrients are all essential for normal metabolic function, and deficiency is particularly unfortunate during pregnancy, lactation and childhood (Cusick and Georgieff 2016; Keen et al. 2003). Micronutrient deficiencies may have both short- and longterm outcomes for the offspring, and a balanced, diverse and 
nutritious diet is recommended to meet nutritional needs during these life periods (Gernand et al. 2016). As vegetarian diets are particularly popular among young women (Alles et al. 2017), the increasing popularity of vegetarian diets may be a public health concern. To obtain an adequate intake of all essential micronutrients, a vegetarian diet must be well planned, and fortified foods and micronutrient supplements are needed (Melina et al. 2016), something which requires nutritional knowledge and adequate nutritional counseling.

\section{Aims}

We have conducted a survey among Norwegian medical students to investigate nutritional knowledge concerning vegetarian diets among well-educated young people. We wanted to examine if there was a difference in nutritional knowledge between students who ever followed a vegetarian diet compared to students who always followed an omnivore diet. Additionally, as future medical doctors, these students are expected to provide adequate nutritional guidance to their patients.

\section{Subjects and methods}

\section{Study population and design}

The medical degree program in Norway is available at four universities and has a duration of 6 years. Entering the Norwegian medical program requires high grade points, and the acceptance rate is equally low at the four universities. In 2017, there were a total of 3875 registered medical students in Norway, and 880 (23\%) of them studied at the University of Bergen (UiB). All medical students at UiB were invited to take part in an online survey on nutritional knowledge in the fall semester of 2018. The survey included a 36-item questionnaire covering information about demographics, former and current diet, use of micronutrient supplements, tobacco and alcohol, in addition to food attitudes and nutritional knowledge. The survey was created using the online survey tool SurveyMonkey (SurveyMonkey.com, LLC, Palo Alto, CA, USA) and was advertised on the website of the Medical Faculty, University of Bergen. All data were collected anonymously and in accordance with the Declaration of Helsinki and approved by the Norwegian Centre for Research Data (NSD), reference 108,552.

\section{Assessment of dietary practice, food attitudes and nutritional knowledge}

The students were asked about ethnicity, age, weight, height, physical exercise and use of alcohol, tobacco and micronutrient supplements. The students reported their former and current diet: omnivore, vegetarian [plant food, in addition to dairy products (lacto-vegetarian) and/or egg (lacto-ovo-vegetarian)] and vegan (plant food only). Nutritional knowledge concerning risk of micronutrient deficiency with a vegan diet and dietary sources of iodine and vitamin B12 were tested by agreement with different statements. The students were categorized into two groups based on their former and current diet: always omnivores (omnivore) versus ever following a vegetarian/vegan diet (vegetarian).

\section{Statistical analysis}

Descriptive statistics were calculated for each survey item. Categorical data are presented as numbers $(\%)$ and compared by chi-square test. Continuous data are presented as mean and standard deviation (SD) or median and interquartile range (IQR), compared by Mann-Whitney $\mathrm{U}$ test. Two-sided $p$ values $<0.05$ were considered statistically significant. The SPSS statistical program (version 25) was used for the statistical analyses.

\section{Results}

\section{Demographics}

A total of 394 of the 880 (45\%) students responded to the survey. Almost one fourth of the students ( $n=95 / 394,24 \%)$ reported former or current use of a vegetarian or vegan diet, with a significant female dominance ( $28 \%$ of the women and $10 \%$ of the men, $p<0.001)$. Baseline demographic characteristics according to former and current diet (omnivores versus vegetarians) are shown in Table 1 . The majority of the students $(n=354 / 394,90 \%)$ reported having a current omnivore diet, while $40 / 394$ students $(10 \%)$ had a vegetarian diet, of which 32 students $(8 \%)$ were vegetarians and 8 students (2\%) vegans.

The students were mainly young people (range 1847 years) and evenly distributed among the 6 years of medical school. The majority (79\%) were women, and 94\% had European origin. None of the current vegetarian/vegan students had children, while 21 omnivore students had one or several children.

There were no differences between vegetarian and omnivore students concerning BMI, regular exercise, use of tobacco or use of alcohol (Table 1). Dieting during the last year was reported by $18 \%$ of the vegetarians and by $15 \%$ of the omnivores $(p=0.56)$.

Regular use of micronutrient supplements $(\geq 3$ days per week) was reported by $52 \%$ of the students. Intake of multivitamins/minerals and iron was more common among vegetarians than omnivores. Sixty-nine percent of the current vegetarians and $75 \%$ of the current vegans used a 
Table 1 Baseline characteristics of the Norwegian medical students according to their former and current diet $(n=394)$

\begin{tabular}{|c|c|c|c|}
\hline Parameters & Vegetarian $N=95$ & Omnivore $N=299$ & $P$ value \\
\hline Women, number (\%) & $87(92 \%)$ & $226(76 \%)$ & $0.001 *$ \\
\hline Age, years, mean (SD) & $23.5(3.2)$ & $23.6(3.7)$ & $0.87 * *$ \\
\hline BMI, kg/m², median (IQR) & $22.3(20.4,23.5)$ & $22.5(20.8,24.2)$ & $0.13 * *$ \\
\hline Regular exercise, $n(\%)$ & $84(88 \%)$ & $275(92 \%)$ & $0.29^{*}$ \\
\hline Hours per week, median (IQR) & $3.5(2.0,5.0)$ & $4.0(2.9,6.0)$ & $0.26 * *$ \\
\hline \multicolumn{4}{|l|}{ Regular use of tobacco, $n(\%)$} \\
\hline Cigarettes & $2(2 \%)$ & $2(1 \%)$ & $0.22 *$ \\
\hline Snuff & $10(11 \%)$ & $32(11 \%)$ & $0.85^{*}$ \\
\hline Regular use of alcohol, $n(\%)$ & $77(81 \%)$ & $247(83 \%)$ & $0.73^{*}$ \\
\hline Units per week, median (IQR) & $2.0(0.5,5.0)$ & $2.0(0.5,4.0)$ & $0.64 * *$ \\
\hline \multicolumn{4}{|c|}{ Regular use of supplements, ( $\geq 3$ days/week), $n(\%)$} \\
\hline Multivitamins/minerals & $46(48 \%)$ & $63(21 \%)$ & $<0.001 *$ \\
\hline Iron & $17(18 \%)$ & $33(11 \%)$ & $0.08^{*}$ \\
\hline Cod liver oil & $19(20 \%)$ & $73(24 \%)$ & $0.38^{*}$ \\
\hline Omega 3 fatty acids & $27(28 \%)$ & $68(23 \%)$ & $0.26^{*}$ \\
\hline
\end{tabular}

${ }^{*}$ Comparison by Pearson chi-square test

** Comparison by Mann-Whitney test

multivitamin/mineral supplement. The most popular type of supplement was, however, cod liver oil and omega 3 fatty acids, being used by $39 \%$ of the students, with no difference between vegetarians and omnivores (Table 1).

\section{Attitudes toward vegetarian diets}

More vegetarian students (44\%) than omnivore students $(13 \%)$ considered a vegetarian diet to be healthier than an omnivore diet $(p<0.001)$ and a vegan diet to be healthier than a vegetarian diet (vegetarian $16 \%$ versus omnivore $2 \%$, $p<0.001$ ).

Among the vegetarians, $45 \%$ did not consider it necessary to take supplements while having a vegetarian diet compared to $28 \%$ of the omnivores $(p=0.004)$, and $61 \%$ of the vegetarians considered it possible to have a well-balanced diet free of meat, fish, dairy products and eggs, i.e., a vegan diet, compared to $38 \%$ of the omnivores $(p<0.001)$.

\section{Nutritional knowledge about a vegan diet}

The students were asked about the risk of specific micronutrient deficiencies associated with a vegan diet (Table 2). Most students (81\%) were aware of the risk of vitamin B12 deficiency. Risk of deficiency for other micronutrients was considered by $74 \%$ of the students for omega 3 fatty acids, $70 \%$ for iron, $56 \%$ for vitamin $\mathrm{D}$, $55 \%$ for iodine, $53 \%$ for folate, $43 \%$ for selenium, $42 \%$ for zinc and $33 \%$ for vitamin A. More vegetarians than omnivores knew about the risk of vitamin B12 deficiency while having a vegan diet; however, more omnivores than vegetarians were aware of the risk of deficiency in four of nine other micronutrients (Table 2).

\section{Nutritional knowledge about dietary sources of vitamin B12 and iodine}

Data regarding knowledge about dietary sources of vitamin B12 and iodine among vegetarian and omnivore students are given in Table 3 . Sixteen percent of the students $(n=64)$ did not answer the questions about dietary sources of vitamin B12, and $18 \%(n=70)$ did not answer the questions about dietary sources of iodine.

As much as a third of all the students thought that beans, lentils and nuts are good sources of vitamin B12 (Table 3). Only $65 \%$ of the omnivore students considered meat to be a good source of vitamin B12 compared to $83 \%$ of the vegetarian students $(p=0.003)$. More omnivores considered fruits $(13 \%)$ and bread $(25 \%)$ to be good sources of vitamin B12 compared to the vegetarians (fruits 6\%,p=0.01; bread 22\%, $p=0.05$ ). Apart from this, no significant differences in knowledge about dietary sources of vitamin B12 were observed between vegetarian and omnivore students $(p>0.06)$.

No differences in knowledge about dietary sources of iodine between vegetarian and omnivore students were observed (Table 3). The most frequently reported source of iodine was table salt, and approximately $20 \%$ of the students reported meat and plant foods to be good sources of iodine (Table 3). 
Table 2 Nutritional knowledge concerning risk of micronutrient deficiencies with a vegan diet among Norwegian medical students according to former and current diet $(n=394)$

\begin{tabular}{lll}
\hline If you do not eat meat, fish, dairy products or eggs, & \multicolumn{2}{l}{ Number $(\%)$ of students who agree } \\
\cline { 2 - 3 } you can get a deficiency in the following micronutrients & Vegetarian & Omnivore \\
& $\mathrm{N}=95$ & $\mathrm{~N}=299$ \\
\hline Vitamin B12 & $85(90 \%)^{*}$ & $232(78 \%)^{*}$ \\
Omega 3 fatty acids & $68(72 \%)^{*}$ & $222(74 \%)^{*}$ \\
Iron & $66(70 \%)$ & $208(70 \%)$ \\
Vitamin D & $55(58 \%)$ & $167(56 \%)$ \\
Iodine & $51(54 \%)$ & $164(55 \%)$ \\
Folate & $46(48 \%)^{*}$ & $163(55 \%)^{*}$ \\
Selenium & $36(38 \%)^{*}$ & $135(45 \%)^{*}$ \\
Zinc & $37(39 \%)^{*}$ & $130(44 \%)^{*}$ \\
Vitamin A & $26(27 \%)^{*}$ & $102(34 \%)^{*}$ \\
\hline
\end{tabular}

*Comparison by Pearson chi-square test; $p \leq 0.05$

\section{Discussion}

The prevalence of current vegetarians among Norwegian medical students was $8 \%$, and the prevalence of current vegans was $2 \%$, but $24 \%$ of the students reported ever following a vegetarian diet. Following a vegetarian diet was more common among female than male students. Among the vegetarian students, $45 \%$ did not consider it necessary to take supplements while following a vegetarian diet, and $61 \%$ considered it possible to have a well-balanced vegan diet. Plant foods were wrongly considered to be a good source of vitamin B12 by $33 \%$ of the students and a good source of iodine by $20 \%$ of the students. Nutritional knowledge regarding vegetarian and vegan diets was not satisfactory among Norwegian medical students and did not differ according to the former and current diet.

\section{Food habits among medical students}

The prevalence of current vegetarians was $8 \%$, and the prevalence of current vegans was $2 \%$; female students were more likely to follow a vegetarian diet than their male colleagues. These findings are in accordance with reports from other countries (Alles et al. 2017; Spencer et al. 2007).

In our study population, regular use of multivitamin/ mineral supplements was significantly more common among

Table 3 Nutritional knowledge about dietary sources of vitamin B12 and iodine among Norwegian medical students $(n=394)$

\begin{tabular}{|c|c|c|c|c|}
\hline \multirow[t]{3}{*}{ The following food is a good source of } & \multicolumn{4}{|c|}{ Number $(\%)$ of students who agree } \\
\hline & \multicolumn{2}{|c|}{ Vitamin B12 } & \multicolumn{2}{|l|}{ Iodine } \\
\hline & $\begin{array}{l}\text { Vegetarian } \\
\mathrm{N}=95\end{array}$ & $\begin{array}{l}\text { Omnivore } \\
\mathrm{N}=299\end{array}$ & $\begin{array}{l}\text { Vegetarian } \\
N=95\end{array}$ & $\begin{array}{l}\text { Omnivore } \\
N=299\end{array}$ \\
\hline Meat & $79(83 \%)^{*}$ & $194(65 \%)^{*}$ & $24(25 \%)$ & $77(26 \%)$ \\
\hline Fatty fish & $56(59 \%)$ & $150(50 \%)$ & $40(42 \%)$ & $125(42 \%)$ \\
\hline Lean fish & & & $54(57 \%)$ & $156(52 \%)$ \\
\hline Dairy products & $57(60 \%)$ & $145(49 \%)$ & $45(47 \%)$ & $150(50 \%)$ \\
\hline Eggs & $63(66 \%)$ & $180(60 \%)$ & $42(44 \%)$ & $121(41 \%)$ \\
\hline Fruit & $6(6 \%)^{*}$ & $38(13 \%)^{*}$ & $4(4 \%)$ & $15(5 \%)$ \\
\hline Vegetables & $21(22 \%)$ & $84(28 \%)$ & $22(23 \%)$ & $63(21 \%)$ \\
\hline Whole wheat bread & $21(22 \%)^{*}$ & $76(25 \%)^{*}$ & $15(16 \%)$ & $57(19 \%)$ \\
\hline Beans, lentils, nuts & $31(33 \%)$ & $98(33 \%)$ & $21(22 \%)$ & $64(21 \%)$ \\
\hline Soy products & $16(17 \%)$ & $37(12 \%)$ & $12(13 \%)$ & $45(15 \%)$ \\
\hline Table salt & - & - & $65(68 \%)$ & $182(61 \%)$ \\
\hline
\end{tabular}

*Comparison by Pearson chi-square test; $p \leq 0.05$ 
vegetarians than omnivores, but we also observed that a quarter of the current vegan students did not use a multivitamin/ mineral supplement. In comparison, a recent Finnish study showed that $91 \%$ of vegans took vitamin B12 supplements and $77 \%$ took vitamin D supplements (Elorinne et al. 2016).

\section{Perceived nutritional status in vegans and vegetarians}

Vegetarians are reported to have lower prevalence of overweight, ischemic heart disease and diabetes, but overall mortality is similar between vegetarians and comparable nonvegetarians (Appleby and Key 2016). Unexpectedly, only $44 \%$ of the Norwegian vegetarian students considered a vegetarian diet to be healthier than eating meat and fish. Vegetarians are also considered to have better health behavior, i.e., they are more physically active, drink less alcohol and smoke less (Baines et al. 2007; Pollard et al. 2001). Our data, based on a rather uniform cohort of medical students, does not confirm this as we did not observe any differences between vegetarian and omnivore students concerning BMI, regular exercise, and use of tobacco or alcohol.

Sixty percent of vegetarians and $40 \%$ of omnivores considered it possible to have a well-balanced vegan diet, and almost half of the vegetarians did not consider it necessary to take supplements while followng a vegetarian diet. Recent reports do not support this view. A Danish study showed that vegans who used supplements did not reach the Nordic Nutritional Recommendations for vitamin $\mathrm{D}$, iodine and selenium, and vegan women also failed to reach the recommendation for vitamin A intake (Kristensen et al. 2015). In the Finnish study, vegans had lower levels of vitamin $D$, vitamin $B 12$, vitamin $E$, $\beta$-carotene, iodine, selenium and ferritin compared to omnivores, even if they used supplements (Elorinne et al. 2016). The highest prevalences of vitamin and mineral deficiencies in a study of Swiss vegetarians and vegans were $58 \%$ for vitamin B6 and 34\% for niacin in the vegetarian group and $47 \%$ for zinc in the vegan group (Schupbach et al. 2017). Altogether these studies confirm the need for adequate micronutrient supplementation while having a vegetarian or vegan diet. Considering the fact that vegetarian diets are increasingly popular among young women, advocating for sufficient micronutrient supplementation is especially important, as maternal micronutrient deficiencies may affect fetal development (Cusick and Georgieff 2016; Pawlak 2017).

\section{Nutritional knowledge about a vegan diet}

A vegan diet is associated with an increased risk of vitamin $\mathrm{B} 12$, vitamin $\mathrm{A}$, vitamin $\mathrm{D}$, iodine, zinc, selenium, iron and omega 3 fatty acid deficiency (Davey et al. 2003; Elorinne et al. 2016; Saunders et al. 2013; Schupbach et al. 2017). Most students $(81 \%)$ agreed on the risk of vitamin B12 deficiency, and $74 \%$ considered it to be a risk of omega 3 fatty acid deficiency. While there is uniform agreement on the risk of vitamin B12 deficiency with the elimination of animalbased foods (Elorinne et al. 2016), the risk of omega 3 fatty acid deficiency is questionable, as the body can synthetize long chain fatty acids from linoleic acid (omega-6) and alpha-linolenic acid (omega-3), which are abundant in seeds and nuts (Harris 2014). However, our study found that cod liver oil and omega 3 fatty acids, and not vitamin B12, were the most popular type of supplements, used by both vegetarians and omnivores.

Significantly more vegetarian than omnivore students knew that a vegan diet was associated with a risk of vitamin B12 deficiency, while more omnivore than vegetarian students thought there might be a risk of deficiency for several other micronutrients. This implies that people who ever used a vegetarian diet might be aware of the risk of vitamin B12 deficiency, but are less knowledgeable about other possible micronutrient deficiencies.

\section{Nutritional knowledge about dietary sources of vitamin B12 and iodine}

Meat, fish, dairy products and eggs are considered to be good dietary sources of vitamin B12 (Allen 2008). The vegetarians had slightly better knowledge about dietary sources of vitamin B12 compared to the omnivores, but as much as one third of the student population considered plant foods to be a good source of vitamin B12. Unless contaminated by soil or vitamin B12 producing bacteria, fruits, vegetables, beans, lentils, nuts, bread, fermented soy products or seaweed will not contain vitamin B12 (Allen 2008).

Fish and dairy products are considered good sources of iodine (Nystrom et al. 2016). Lean fish contains more iodine than fatty fish, and many students were not aware of this difference. While eggs contain some iodine, whole wheat bread, meat, fruits, vegetables, beans, lentils and nuts contain insignificant amounts of iodine (Medin et al. 2020). In many countries, iodine is added to table salt, but in Norway "iodized salt" is rarely used and fortified products are uncommon. The majority of students wrongly reported table salt to be a good source of iodine and as much as $18 \%$ of the students did not answer any questions about sources of iodine. Pregnant and lactating women of the Nordic countries have been found to have mild iodine deficiency (Medin et al. 2020), and the lack of knowledge about dietary sources of iodine among Norwegian medical students is concerning.

\section{Evaluation of nutritional status is difficult}

Deficiency of several essential micronutrients has been found in well-educated Australian female students, including those studying nutrition (Fayet-Moore et al. 2014); therefore, 
nutritional assessment, even of your own diet, is obviously difficult. The Norwegian Directorate of Health recommends inhabitants who have a vegetarian diet "to keep an eye on vitamin B2, B6, B12, D, iron, selenium, zinc and iodine" to ensure they get enough of these micronutrients (Helsedirektoratet 2015). As our study shows, Norwegian medical students do not have enough nutritional knowledge to do so, not even those who ever had a vegetarian diet.

Published reports also differ on risk assessment for various micronutrients in vegetarian diets (Gibson et al. 2014), and there is no clear agreement on the recommended intake of several micronutrients and on what constitutes an adequate status (Green et al. 2017). Finally, for many micronutrients, such as biotin (Tokuriki et al. 2013), there is no correct methodology to evaluate biochemical status. With the growing interest in vegetarian diets, the role of health professionals will be even more important in the future to secure sufficient nutritional status among those who exclude animal foods from the diet.

\section{Nutrition education in the medical curriculum}

Vegetarians in the general population need nutritional education and guidance to be able to secure an adequate micronutrient status. In a survey conducted by the American Dietetic Association, $61 \%$ of the respondents considered their family doctor to be a "very credible" source of nutritional information (American Dietetic Association 2008), but in a cohort of resident physicians this view was not shared, as the majority (86\%) considered themselves inadequately trained to provide nutritional counseling (Vetter et al. 2008). In our study, students from all 6 years were evenly represented, and their knowledge did not differ significantly, reflecting a lack of nutritional education throughout the medical curriculum in Norway.

Our findings are similar to those found in a recent review on nutrition knowledge, skills and confidence to counsel patients among medical students. This analysis showed that nutrition is insufficiently incorporated into the medical education, regardless of country, setting or year of medical education, and the students are not supported to provide high-quality, effective nutrition care (Crowley et al. 2019). Nutrition education needs to be improved in the medical curriculum to help doctors provide adequate nutritional care for their patients.

\section{Study limitations}

The survey had a low response rate $(45 \%)$, which reduces the generalizability. As much as $16-18 \%$ of the students did not answer any questions about dietary sources of vitamin B12 and iodine. The low response rate may reflect a lack of interest or knowledge in the subject. If only interested or knowledgeable students responded to the survey, nutritional knowledge among Norwegian medical students may be even worse than we have observed.
The questionnaire has not been validated and included multiple-choice questions, which may induce overestimation of knowledge. Response bias, i.e., the tendency to respond inaccurately or falsely, was also suspected for some questions. For example, in the question where we asked about the risk of micronutrient deficiency when following a vegan diet, $53 \%$ of the students answered yes to folate being a micronutrient at risk. As a vegan diet is not associated with a deficiency of folate, a vitamin abundant in plants (Allen 2008), these results may indicate that the students did not know the answer to the question and just randomly picked an answer. Our population may not be representative of all medical students in Norway, but the medical curriculum is approximately identical at the four universities in Norway.

\section{Conclusion}

Our study demonstrates a lack of nutritional knowledge about vegetarian diets among well-educated Norwegian medical students, even among those who ever had a vegetarian diet. Vegetarian diets are increasing in popularity, particularly among young females, and as vegetarians are subject to various micronutrient deficiencies, this is a matter of public health concern. Nutritional knowledge needs to be improved in the general population. To make doctors capable of providing adequate nutritional guidance to their patients, a more extensive integration of nutritional training in the medical curriculum should be implemented.

Acknowledgements We thank the medical students at the University of Bergen for their participation in the study.

Authorship contributions Ingebjørg Sanne: Conceptualization, Methodology, Investigation, Writing-Reviewing and Editing.

Anne-Lise Bjørke Monsen: Conceptualization, Methodology, Investigation, Writing-Reviewing and Editing.

Funding information Open Access funding provided by University of Bergen. This research did not receive any specific grant from funding agencies in the public, commercial, or not-for-profit sectors.

\section{Compliance with ethical standards}

The paper meets ethical standards. All data was collected anonymously and in accordance with the Declaration of Helsinki and approved by the Norwegian Centre for Research Data (NSD), reference 108552.

Conflict of interest The authors have no financial relationships to disclose or no conflicts of interest relevant to this article.

Open Access This article is licensed under a Creative Commons Attribution 4.0 International License, which permits use, sharing, adaptation, distribution and reproduction in any medium or format, as long as you give appropriate credit to the original author(s) and the source, provide a link to the Creative Commons licence, and indicate if changes were made. The images or other third party material in this article are included 
in the article's Creative Commons licence, unless indicated otherwise in a credit line to the material. If material is not included in the article's Creative Commons licence and your intended use is not permitted by statutory regulation or exceeds the permitted use, you will need to obtain permission directly from the copyright holder. To view a copy of this licence, visit http://creativecommons.org/licenses/by/4.0/.

\section{References}

Allen LH (2008) Causes of vitamin B12 and folate deficiency. Food Nutr Bull 29:S20-S34. discussion S35-27. https://doi.org/10.1177/ 15648265080292 s 105

Alles B, Baudry J, Mejean C, Touvier M, Peneau S, Hercberg S, KesseGuyot E (2017) Comparison of Sociodemographic and Nutritional Characteristics between Self-Reported Vegetarians, Vegans, and Meat-Eaters from the NutriNet-Sante. Study Nutrients 9. https:// doi.org/10.3390/nu9091023

AmericanDieteticAssociation (2008) Nutrition and You: Trends 2008. http://www.eatrightpro.org/ /media/eatrightprofiles/media/ trendsandreviews/nutritionandyou/trends_2008_where_did_you_ hear that.ashx. Accessed 03 March 2019

Appleby PN, Key TJ (2016) The long-term health of vegetarians and vegans. Proc Nutr Soc 75:287-293. https://doi.org/10.1017/ S0029665115004334

Baines S, Powers J, Brown WJ (2007) How does the health and wellbeing of young Australian vegetarian and semi-vegetarian women compare with non-vegetarians? Public Health Nutr 10:436-442. https://doi.org/10.1017/S1368980007217938

Crowley J, Ball L, Hiddink GJ (2019) Nutrition in medical education: a systematic review. Lancet Planet Health 3:e379-e389. https://doi. org/10.1016/s2542-5196(19)30171-8

Cusick SE, Georgieff MK (2016) The role of nutrition in brain development: the golden opportunity of the "first 1000 days". J Pediatr 175: 16-21. https://doi.org/10.1016/j.jpeds.2016.05.013

Davey GK, Spencer EA, Appleby PN, Allen NE, Knox KH, Key TJ (2003) EPIC-Oxford: lifestyle characteristics and nutrient intakes in a cohort of 33883 meat-eaters and 31546 non meat-eaters in the UK. Public Health Nutr 6:259-269. https://doi.org/10.1079/ PHN2002430

Elorinne AL et al (2016) Food and Nutrient Intake and Nutritional Status of Finnish Vegans and Non-Vegetarians. PloS one 11:e0148235. https://doi.org/10.1371/journal.pone.0148235

Fayet-Moore F, Petocz P, Samman S (2014) Micronutrient status in female university students: iron, zinc, copper, selenium, vitamin B12 and folate nutrients 6:5103-5116. https://doi.org/10.3390/ nu6115103

Gernand AD, Schulze KJ, Stewart CP, West KP Jr, Christian P (2016) Micronutrient deficiencies in pregnancy worldwide: health effects and prevention. Nat Rev Endocrinol 12:274-289. https://doi.org/10. 1038/nrendo.2016.37

Gibson RS, Heath AL, Szymlek-Gay EA (2014) Is iron and zinc nutrition a concern for vegetarian infants and young children in industrialized countries? Am J Clin Nutr 100(Suppl 1):459S-468S. https://doi.org/ 10.3945/ajen.113.071241

Green R et al (2017) Vitamin B12 deficiency nature reviews disease primers 3:17040. https://doi.org/10.1038/nrdp.2017.40
Harris WS (2014) Achieving optimal n-3 fatty acid status: the vegetarian's challenge...Or not. Am J Clin Nutr 100(Suppl 1):449S-452S. https://doi.org/10.3945/ajen.113.071324

Helsedirektoratet (2011) (The Norwegian Directorate of Health) Nasjonalt råd for ernæring. Kostråd for å fremme folkehelsen og forebygge kroniske sykdommer. Metodologi og vitenskapelig kunnskapsgrunnlag. https://helsedirektoratet.no/publikasjoner/ kostrad-for-a-fremme-folkehelsen-og-forebygge-kroniskesykdommer-metodologi-og-vitenskapelig-kunnskapsgrunnlag. Accessed 28 August 2019

Helsedirektoratet (2015) (The Norwegian Directorate of Health) Næringsstoffer du må følge med på. https://helsenorge.no/ kosthold-og-ernaring/vegetarisk-kosthold/pass-pa-naringsstoffervegetar. Accessed 03 March 2019

Keen CL et al (2003) The plausibility of micronutrient deficiencies being a significant contributing factor to the occurrence of pregnancy complications J Nutr 133:1597S-1605S. https://doi.org/10.1093/jn/133. $5.1597 \mathrm{~S}$

Kristensen NB et al (2015) Intake of macro- and micronutrients in Danish vegans. Nutr J 14:115. https://doi.org/10.1186/s12937-015-0103-3

Medin AC, Carlsen MH, Andersen LF (2020) Iodine intake among children and adolescents in Norway: estimates from the national dietary survey Ungkost 3 (2015-2016). J Trace Elem Med Biol : Organ Soc Min Trace Elem 58:-126427. https://doi.org/10.1016/j.jtemb.2019. 126427

Melina V, Craig W, Levin S (2016) Position of the academy of nutrition and dietetics: vegetarian diets. J Acad Nutr Diet 116:1970-1980. https://doi.org/10.1016/j.jand.2016.09.025

Nystrom HF et al (2016) Iodine status in the Nordic countries - past and present. Food Nutr Res 60:31969. https://doi.org/10.3402/fnr.v60. 31969

Pawlak R (2017) To vegan or not to vegan when pregnant, lactating or feeding young children. Eur J Clin Nutr 71:1259-1262. https://doi. org/10.1038/ejen.2017.111

Pollard J, Greenwood D, Kirk S, Cade J (2001) Lifestyle factors affecting fruit and vegetable consumption in the UK Women's. Cohort Study Appetite 37:71-79. https://doi.org/10.1006/appe.2001.0415

Saunders AV, Davis BC, Garg ML (2013) Omega-3 polyunsaturated fatty acids and vegetarian diets. Med J Aust 199:S22-S26

Schupbach R, Wegmuller R, Berguerand C, Bui M, Herter-Aeberli I (2017) Micronutrient status and intake in omnivores, vegetarians and vegans in Switzerland. Eur J Nutr 56:283-293. https://doi.org/ 10.1007/s00394-015-1079-7

Spencer EH, Elon LK, Frank E (2007) Personal and professional correlates of US medical students' vegetarianism. J Am Diet Assoc 107: 72-78. https://doi.org/10.1016/j.jada.2006.10.034

TheVeganSociety (2019) Statistics 2019. https://www.vegansociety.com/ news/media/statistics. Accessed 28 August 2019

Tokuriki S et al (2013) Biotin and carnitine profiles in preterm infants in Japan Pediatr Int 55:342-345. https://doi.org/10.1111/ped.12053

Vetter ML, Herring SJ, Sood M, Shah NR, Kalet AL (2008) What do resident physicians know about nutrition? An evaluation of attitudes, self-perceived proficiency and knowledge. J Am Coll Nutr 27:287-298. https://doi.org/10.1080/07315724.2008.10719702

Publisher's note Springer Nature remains neutral with regard to jurisdictional claims in published maps and institutional affiliations. 